OPEN ACCESS

Edited by:

Agnieszka Ludwików, Adam Mickiewicz University in Poznań, Poland

Reviewed by: Gian Attilio Sacchi,

Università degli Studi di Milano, Italy Karabi Datta,

University of Calcutta, India

*Correspondence: Anu P. Minhas annuminhas@gmail.com; priyacoa@rediffmail.com

Specialty section: This article was submitted to

Plant Biotechnology, a section of the journal Frontiers in Plant Science

Received: 27 January 2018 Accepted: 15 June 2018 Published: 10 July 2018

Citation: Minhas AP, Tuli R and Puri S (2018) Pathway Editing Targets for Thiamine Biofortification in Rice Grains. Front. Plant Sci. 9:975 doi: 10.3389/fpls.2018.00975

\section{Pathway Editing Targets for Thiamine Biofortification in Rice Grains}

\author{
Anu P. Minhas*, Rakesh Tuli and Sanjeev Puri \\ Department of Biotechnology, University Institute of Engineering and Technology, Panjab University, Chandigarh, India
}

Thiamine deficiency is common in populations consuming polished rice as a major source of carbohydrates. Thiamine is required to synthesize thiamine pyrophosphate (TPP), an essential cofactor of enzymes of central metabolism. Its biosynthesis pathway has been partially elucidated and the effect of overexpression of a few genes such as thit and thiC, on thiamine accumulation in rice has been reported. Based on current knowledge, this review focuses on the potential of gene editing in metabolic engineering of thiamine biosynthesis pathway to improve thiamine in rice grains. Candidate genes, suitable for modification of the structural part to evolve more efficient versions of enzymes in the pathway, are discussed. For example, adjacent cysteine residues may be introduced in the catalytic domain of thi4 to improve the turn over activity of thiamine thiazole synthase 2. Motif specific editing to modify promoter regulatory regions of genes is discussed to modulate gene expression. Editing cis acting regulatory elements in promoter region can shift the expression of transporters and thiamine binding proteins to endosperm. This can enhance dietary availability of thiamine from rice grains. Differential transcriptomics on rice varieties with contrasting grain thiamine and functional genomic studies will identify more strategic targets for editing in future. Developing functionally enhanced foods by biofortification is a sustainable approach to make diets wholesome.

Keywords: biofortification, CRISPR, gene editing, pathway, rice, thiamine, vitamin B1

\section{INTRODUCTION}

Over 2 billion people suffer from different types of malnutrition worldwide (Global Nutrition Report, 2016). The role of vitamins in stress tolerance, growth and development has been reported in human and plants (Hellmann and Mooney, 2010; Galluzzi et al., 2013; Colinas and Fitzpatrick, 2015). Except vitamins B3 (niacin) and D, human body is incapable of synthesizing other vitamins. Because of high water solubility and heat sensitivity, majority of B-type vitamins and vitamin C are lost during cooking, resulting into their deficiency in diets. The average storage span of vitamin B1 in human body is only about 18 days and therefore, it needs to be replenished from diet regularly (Wooley, 2008). This review focuses on the enrichment of food grains with vitamin B1 (also called thiamine or aneurin), taking rice as the model crop and lays emphasis on pathway engineering through genome editing.

\section{MINI-REVIEW}

Consuming less than recommended daily dose of vitamin B1 (0.2 to $1.5 \mathrm{mg}$ in infants to adults) results in beriberi/Wernicke-Korsakoff syndrome (Joint FAO/WHO Expert Consultation, 2004) (Supplementary Table 1). Women develop symptoms of edema and paresthesia whereas infants 
show acute cardiac failure, gastrointestinal symptoms and lactic acidosis, resulting in increased mortality (Keating et al., 2014; Moulin et al., 2014; Porter et al., 2014; Barennes et al., 2015). Limited information is available on prevalence of thiamine deficiency worldwide. Among underdeveloped countries, in South East Asia alone, 27-78\% mothers and 15-58\% children are reported deficient in thiamine (Keating et al., 2014; Whitfield et al., 2017). Consuming high dose of thiamine is reported to reduce the development of nuclear cataract and lens opacification. In Type 2 diabetic patients, thiamine therapy is recommended to reverse the process of micro albuminuria (Cumming et al., 2000; Jacques et al., 2005; Rabbani et al., 2009). Fruits, nuts, fermented food products, majority pulses, seafood, meat and meat products are good sources of thiamine. Contrary to this, majority staple crops including rice are either deficient in thiamine or store it in inedible plant parts (USDA, 2013). Information about thiamine content and estimated fold increase required in different food types to meet recommended daily allowance (RDA) of thiamine is given in Supplementary Table 2.

\section{RATIONALE BEHIND THIAMINE DEFICIENCY IN DEVELOPING COUNTRIES}

Approximately 375 million people worldwide and around 30\% of Indian population is vegetarian (Chemnitz and Becheva, 2014). Rice (Oryza sativa) alone contributes to $27-80 \%$ of food energy in developing countries (FAO, 2011). Thiamine content in rice (per $100 \mathrm{~g}$ of grains) ranges from $0.053 \mathrm{mg}$ (Poland variety, polished) to $3.03 \mathrm{mg}$ (Indonesian variety, unpolished) (Supplementary Table 3). Elimination of rice aleurone layer (where thiamine is predominantly stored) reduces thiamine content to $0.11 / 100 \mathrm{~g}$ in polished rice grains which further reduces to $0.01 \mathrm{~g} / 100 \mathrm{~g}$ in cooked rice (Sautter et al., 2006; Mohd Fairulnizal et al., 2015). Consequently, exclusive feeding on white rice diet plan results in thiamine deficiency in human.

\section{APPROACHES TO THIAMINE ENHANCEMENT IN RICE}

In developing countries, chemical fortification of food grains with thiamine encounters problems of lack of food processing industries, affordability, scalability, stability during transport, storage and public distribution (Sautter et al., 2006; Zhu et al., 2007; Mayer et al., 2008). Mononitrate and hydrochloride derivatives of thiamine used to fortify rice grains are heat sensitive and result in taste alteration (Steiger et al., 2014). Biofortification is the most easily applicable and sustainable seed technology in even poorly managed agriculture. Biofortification approaches can be designed to enhance total thiamine content and its bioavailability through thiamine re-localization in crop plants (WHO/NHD, 1999). However, such strategies require detailed knowledge of involved metabolic pathway, transportation and localization of thiamine in edible plant parts.

\section{THIAMINE BIOSYNTHESIS PATHWAY IN RICE}

Thiamine in plants exists as phosphate derivatives, like thiamine monophosphate (TMP), thiamine diphosphate (TDP) and thiamine triphosphate (TTP). TDP, also called as thiamine pyrophosphate (TPP) is the functional form while unphosphorylated thiamine is the transportable form of thiamine in plants and human (Bettendorff et al., 2007; Gangolf et al., 2010). Major steps of thiamine biosynthesis pathway have been described in different organisms (Belanger et al., 1995; Machado et al., 1996; Chabregas et al., 2001; Wang et al., 2006; Ajjawi et al., 2007; Raschke et al., 2007). Based on the information available in KEGG (Kyoto encyclopedia of genes and genomes) database, the thiamine biosynthesis pathway in Escherichia coli, Arabidopsis thaliana and O. sativa is summarized in Figure 1 and enzymes involved are listed in Supplementary Table 4 . The key enzymes of HET-P (4-methyl-5-( $\beta$-hydroxyethyl) thiazole phosphate) branch of thiamine biosynthesis pathway are thiazole synthase (encoded by thiG), thiazole tautomerase (encoded by tenI) and thiamine thiazole synthase 2 (thi4 family gene). Thiazole synthase and thiazole tautomerase are reported in E. coli while thiamine thiazole synthase 2 has only been reported in Arabidopsis and O. sativa. Phosphooxymethyl pyrimidine kinase, pyrimidine precursor biosynthesis enzyme and phosphomethyl pyrimidine synthase encoded by thiD, thi5 and thiC respectively are involved in HMP-PP (2-methyl-4-amino-5-hydroxymethylpyrimidine pyrophosphate) branch of the pathway. The thiD and thi5 are present exclusively in $E$. coli whereas thiC has been identified in all three organisms. HET-P and HMP-PP condensation to TMP in chloroplast is catalyzed by the ubiquitous thiamine biosynthetic bifunctional enzyme (encoded by th1) (Figure 1 and Supplementary Table 4). Synthesized TMP is transported across chloroplast membrane in the form of free thiamine and is phosphorylated to TPP by cytosolic tpk1 encoding thiamine pyrophosphokinase (Ajjawi et al., 2007; Pourcel et al., 2013). The adk1-encoded kinase phosphorylates TPP to TTP in the cytosol. Phosphatases are responsible for dephosphorylating TPP to TMP and further to thiamine. One such phosphatase encoded by th2 has been identified in Arabidopsis (Mitsuda et al., 1979; Molin and Fites, 1980; Rapala-Kozik et al., 2009). The unidentified enzymes in rice genome are highlighted with a question mark (?) in Figure 1 and Supplementary Table 4.

\section{GENOME EDITING WITH CRISPR-CAS9 ENDONUCLEASE SYSTEM}

A number of approaches for editing DNA sequences have become available in recent years (Pabo et al., 2001; Boch et al., 2009; Moscou and Bogdanove, 2009). However, those requiring protein designing (such as zinc finger nucleases, ZFN and transcription activator like effector nuclease, TALEN) are less versatile, more expensive and complex to apply than the RNA designing based approach. The RNA based approach utilizes clustered regularly interspaced short palindromic repeats (CRISPR) and Cas9 nuclease for gene editing. Though the sequence target 


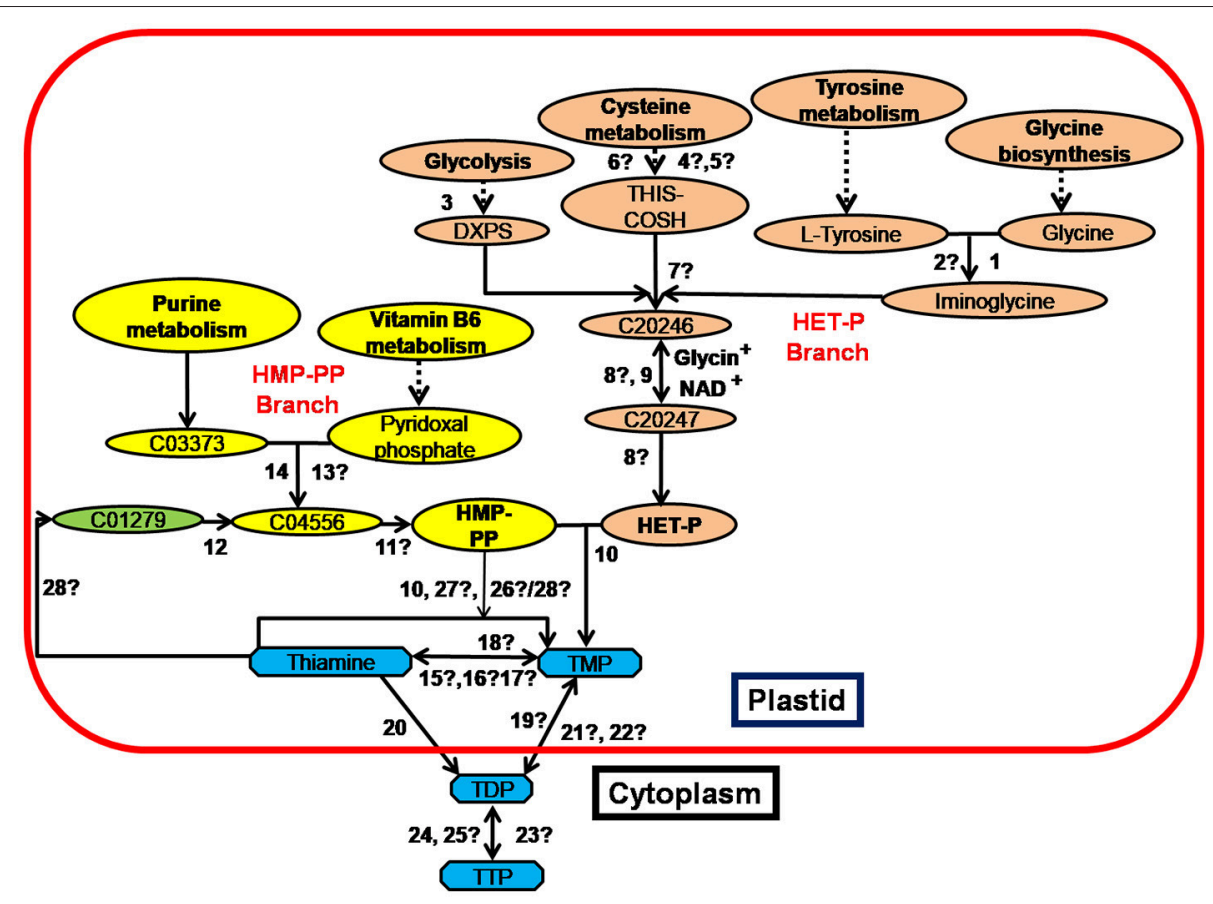

FIGURE 1 | Summary of the Thiamine biosynthesis pathway in E. coli, A. thaliana, and O. sativa (modified from Kyoto encyclopedia of genes and genomes database). The two major branches HMP-PP (2-methyl-4-amino-5-hydroxymethylpyrimidine pyrophosphate) and HET-P (4-methyl-5-( $\beta$-hydroxyethyl) thiazole phosphate) are highlighted in different colors. The intermediates of the pathway are shown in the figure. Details of the enzymes numbered from 1 to 28 are provided in Supplementary Table 4. Unidentified enzymes in rice genome have been indicated with a question mark (?). Discontinuous lines indicate that all steps in the pathway are not shown in the figure.C20246, (2-[(2R,5Z)-2-Carboxy-4-methylthiazol-5(2H)-ylidene] ethyl phosphate); C20246, (2-[(2R,5Z)-2-Carboxy-4-methylthiazol-5(2H)-ylidene] ethyl phosphate); C03373, (Aminoimidazole ribotide); C01279, (4-Amino-5 hydroxymethyl-2-methylpyrimidine); C04556, (4-Amino-5-hydroxymethyl-2-methylpyrimidine phosphate); DXPS, 1-Deoxy-D-xylulose 5-phosphate; TMP, Thiamine monophosphate; TDP, Thiamine diphosphate; TTP, Thiamine triphosphate.

to be edited can be modified by any of these approaches, the level of precision, efficiency and operative details are different for each method. In the CRISPR-Cas9 system, a guide RNA is designed against the target sequence in gene (Gaj et al., 2013; Ji et al., 2015; Jones, 2015; Pan et al., 2016). gRNA-Cas9 complex scans the target DNA for protospacer sequence by searching a protospacer adjacent motif (PAM) and triggers double stranded break in the target sequence (Bolotin et al., 2005; Marraffini and Sontheimer, 2008; Mojica et al., 2005; Garneau et al., 2010; Cong et al., 2013; Hsu et al., 2014). Rapid progress has been made in using CRISPR-Cas9 system in plants for modification of traits (Supplementary Table 5). Two CRISPR-Cas9 edited plants (white button mushroom resistant to browning and Camelina sativa with enhanced omega-3 oil content) have been de-regulated in the US market (Waltz, 2016, 2018). One concern associated with CRISPR/Cas9 editing is the off targeting of very similar sequences and homeologs in polyploid crops (Wang et al., 2014; Li et al., 2015, 2016a; Jiang et al., 2016; Andersson et al., 2017). To improve specificity, strategies such as selecting for high homology between the guide sequence and target region near the PAM site, backcrossing mutant plant to wild parents and promoter selection for expressing gRNA and Cas9 have been suggested (Wang et al., 2015; Chen et al., 2016; Li et al., 2016b; Murugan et al., 2017). Another concern associated with CRISPR/Cas9 is the need for high throughput screening of the mutant lines. A PCR based high-resolution fragment analysis method (HRFA) with 1 bp resolution limit has been developed to facilitate screening of multiple lines (Li et al., 2016b).

\section{ATTEMPTS FOR GENETIC MODIFICATION OF THIAMINE BIOSYNTHESIS PATHWAY}

Among limited attempts made toward thiamine enrichment, none has led to sufficient increase in thiamine content (Supplementary Table 6). The overexpression of native and riboswitch-truncated versions of thiC in Arabidopsis has been reported to show 1.5 and 3.0 fold increase respectively in total seed thiamine. Riboswitch is a conserved sequence at $3^{\prime}$ untranslated region of pre-mRNA in thiC and thi1, which binds TPP (at $500 \mathrm{mM}$ binding constant in Arabidopsis) and induces conformational change resulting in splicing of intron 2 . The intron splicing eliminates polyadenylation signal, making the transcript unstable and therefore negatively regulates thiamine biosynthesis (Croft et al., 2007). The thiC null mutant exhibits severely compromised growth phenotype with low thiamine, TMP and TPP content (Kong et al., 2008; Beatty et al., 2009; Bocobza et al., 2013). Feeding studies with pathway precursor/s increase free thiamine and TPP content in thiC null mutant but the increase in thiamine content is almost equivalent to natural thiamine content in wild type (Pourcel et al., 2013). These findings suggest thiC as an important regulatory enzyme 
of thiamine biosynthesis pathway. However, thiC overexpression alone is not enough to achieve sufficient thiamine enrichment in plants. Simultaneous overexpression of thil/thi4 (osdr8 in rice) and thiC in Arabidopsis increases total thiamine content in leaf and seed by 3.4 and 2.6 fold respectively. Resultant plants exhibit stress tolerance phenotype similar to the wild type. Overexpressing thi4 and thiC in rice increases grain thiamine content by $\sim 5$ fold but display no altered resistance to Xanthomonas oryzae pv. oryzae (Pourcel et al., 2013; Dong et al., 2015, 2016).

\section{TARGET GENES FOR THIAMINE BIOFORTIFICATION THROUGH GENE EDITING}

The above studies suggest that the enrichment of precursors of HET-P and HMP-PP branches in plastid is a pre-requisite to grain thiamine enhancement. To achieve HET-P enrichment, enzymes with a question mark (?) from number 1-8 in Figure 1 (information in Supplementary Table 4) need be identified and characterized in rice. Among these, thil/thi4 enzyme in rice and $S$. cerevisae catalyzes synthesis of thiazole moiety by transferring sulfur from its conserved cysteine residue (cys205) to thiazole precursor. In this reaction, catalytic cysteine residue transforms to a dehydroalanine (Dha) residue by losing its sulfur. Restoration of dehydroalanine (Dha) residue back to cysteine has not been reported, rendering thi4 inactive in single turnover reaction and therefore, limits HET-P biosynthesis (Chatterjee et al., 2011; Pourcel et al., 2013). Park and Raines (2001) have reported the formation of vicinal disulfide turn by oxidation of adjacent cysteine residues in a protein. The adjacent residues act as an artificial "redox switch" to modulate the conformational stability and catalytic activity of the protein (Carugo et al., 2003). Adjacent disulfide bonds have naturally been reported in many proteins (Ghosh et al., 1995; Gehrmann et al., 1998; Wang et al., 2000). The analysis of sequences of thi4 variants in different rice varieties will identify the target sites for disulphide engineering to improve thi4 turnover by facilitating electron exchange. For HMP-PP enrichment, thiC, the key enzyme of the branch has to be overexpressed, followed by th1 overexpression to accelerate TMP condensation. Synthesized TMP has to be transported efficiently across chloroplastic membrane to cytosol and to seed endosperm by overexpressing tpk encoding thiamine pyrophosphokinase. In seed, genes coding for phosphatases have to be activated to accumulate thiamine in unphosphorylated (bioavailable) form.

Due to divergent expression of HMP-PP and HET-P branches in different plant tissues, seed storage of thiamine is determined by the source to sink movement of thiamine and/or its precursor molecules via membrane transporters. High level of expression of thi4 with negligible thiC expression is reported in maize endosperm and is a direct indicator of pyrimidine import from adjoining tissues (Robbins and Bartley, 1937; Bonner and Buchman, 1938; Rodionov et al., 2002). Martinis et al. (2016) reported put3 in A. thaliana, encoding transporter involved in transporting thiamine and polyamine across phloem tissue.
The put3 mutant shows impaired thiamine distribution among tissues, affecting plant growth. Thiamine is stored as stable complex with thiamine binding proteins (TBP) in peripheral layers of grains. Such proteins have been reported in many crops (maize, oat, faba bean, and garden pea) (Gołda et al., 2004; Pourcel et al., 2013; Blancquaert et al., 2015). However, removal of peripheral layers from cereal grains during milling process results in the loss of vitamin binding proteins and thus, the bound vitamin (Gołda et al., 2004; Pourcel et al., 2013). Therefore, emphasis must be on the identification of tissue specific thiamine transporters required for efficient translocation of thiamine or precursors from photosynthetic tissue to seed and then to the endosperm along with thiamine binding proteins for stable localization.

A number of cis elements required for endosperm specific expression have been identified in promoter sequences ( $\mathrm{Wu}$ et al., 1998; Kawakatsu et al., 2008; Le et al., 2008; Nie et al., 2013). The expression of thil and thiC is also influenced by abiotic factors such as salt, flood and light (Ribeiro et al., 2005). However, the current knowledge of epigenetic response elements in promoter sequences is insufficient to design epigenetic regulation as an approach to maximize gene expression in endosperm for enhanced thiamine bioavailability. Thus, the strategies for biofortification will improve, with increase in knowledge of thiamine biosynthesis pathway genes, their regulatory mechanisms, interacting proteins, thiamine specific kinases, phosphatases, tissue specific transporters, and vitamin stabilizing proteins in rice.

\section{NEED TO IDENTIFY GENE-EDITING TARGETS BY ANALYZING RICE VARIETIES WITH CONTRASTING THIAMINE CONTENT}

Goyer and Sweek (2011) have reported significant differences in transcriptome data of two potato cultivars differing two folds in their thiamine content. Differential expression of genes in thiamine contrasting varieties to identify editing targets is an important area that has not received sufficient attention. Only scanty information is available on thiamine associated diversity in rice genotypes (Supplementary Table 3) but no transcriptome information is available for these varieties. Therefore, extensive screening of diverse rice genotypes, including landraces for grain thiamine content can give more clues about genes with differential expression, helping in modifying thiamine biosynthesis pathway in rice. Identification of genes encoding differentially expressed transporters by comparative tissue transcriptomics approach (assisted by laser capture microscopy) in contrasting rice varieties is one such example.

\section{EXPRESSION ANALYSIS OF GENES OF THIAMINE BIOSYNTHESIS PATHWAY FOR EDITING BY CRISPR-CAS9 SYSTEM}

Tissue specific transcriptome data provides transcriptional pattern of genes in different tissues. Among available rice 
expression databases such as "OryzaExpress," “TENOR" (transcriptome encyclopedia of rice), "PLEXdb" (plant expression database) and "RiceXPro" etc., we notice that only "RiceXPro" provides expression values in FPKM (fragments per kilobase of transcript per million mapped reads) for different tissues and growth stages of Nipponbare rice (Hamada et al., 2011; Sato et al., 2011a, 2013; Dash et al., 2012; Takehisa et al., 2012; Kawahara et al., 2016). Hence, the "RiceXPro" database was utilized in this analysis. Even "RiceXPro" does not provide expression information on all the genes of thiamine biosynthesis pathway. The analysis showed level of expression of ncs 1 gene encoding putative allantoin permease (cell membrane transporter), thiC gene encoding phosphomethylpyrimidine synthase, a thiC family gene encoding pentatricopeptide and three tpk genes encoding thiamine pyrophosphokinase paralogs in different tissues. All above genes except tpk2 (2.18487 FPKM in endosperm) show negligible expression in endosperm and whole seed (Table 1).

The promoter sequence regions of three rice $t p k$ variants were analyzed for the presence of endosperm-specific cis elements. The sequences showed the presence of AACA motif, ACGT motif, Prolamin box and TATA box in tpk3 promoter sequence, in the region $300 \mathrm{bp}$ upstream of the transcription start site (Thompson et al., 1997; Higo et al., 1999; Supplementary Table 7 and Supplementary Figure 1). An approach to use CRISPR-Cas9 for editing is illustrated by taking the example of tpk3 gene, with the objective of achieving its expression in endosperm tissue. The Supplementary Figure 1, shows the 300 bp promoter region of tpk3 allele (LOC_Os05g30454). Though other motifs are present, the critical motif GCN4 is missing. This can strategically be introduced upstream of the above motifs by editing at a selected position. A 20 bp gRNA sequence with NGG as the PAM is shown, as a suitable target site for gRNA (Supplementary Figure 1). The target site has been selected for its absence of off-site targets in rice genome using E-CRISP and Cas-OFFinder tools respectively (Bae et al., 2014; Heigwer et al., 2014). Three to four nucleotides upstream of the PAM, the DNA is cleaved by Cas9. By transient or stable transformation with the gRNA and Cas9, a GCN4 box can be introduced at the point of editing by co-transformation with oligonucleotides designed to promote homologous recombination in the target region. The absence of GCN4 motif is in agreement with negligible expression of $t p k 3$ in rice endosperm. The resultant edited gene carrying the GCN4 with other endosperm specific motifs will be expected to show endosperm specific expression of tpk3 gene.

In conclusion, complete information about genetic components of thiamine biosynthesis pathway and their regulatory mechanisms is required to redesign the pathway for high level expression of thiamine in grain endosperm. Thiamine biosynthesis pathway mentioned for rice in this study identifies a list of uncharacterized genes (thiH, thiG/thiS, thiF, thiD, phoA, aphA, thiK etc.). Genes coding for thiamine specific transporters, kinases, and phosphatases need to be identified in rice genome. These are required to carry thiamine precursors and synthesize thiamine to endosperm in bioavailable form. Identification of thiamine stabilizing proteins and their level of expression in rice endosperm are important to ensure high level of stable thiamine in agronomically elite varieties. Genes have been shortlisted for modifying structural part to encode more efficient version of proteins (thi1/thi4) and the expression level of the candidate gene can be modulated by promoter engineering ( $t p k$, thiC and thi4/th1). To transport synthesized thiamine or its precursors efficiently to endosperm of rice grain, introducing cis elements to the promoters by

TABLE 1 | Analyses of the tissue specific expression of genes of thiamine biosynthesis pathway derived from "RiceXPro" database (Sato et al., 2011a,b, 2013).

\begin{tabular}{|c|c|c|c|c|c|c|c|c|}
\hline Gene Name & Locus ID & $\begin{array}{l}\text { Chrom. } \\
\text { number }\end{array}$ & $\begin{array}{l}\text { Chrom. } \\
\text { locus }\end{array}$ & $\begin{array}{l}\text { No. of amino } \\
\text { acids } \\
\text { encoded }\end{array}$ & $\begin{array}{l}\text { Corresponding } \\
\text { orthologs } \\
\text { present }\end{array}$ & $\begin{array}{l}\text { Maximum } \\
\text { expression } \\
\text { (tissue/ FPKM) }\end{array}$ & $\begin{array}{l}\text { Expression level in } \\
\text { endosperm/whole } \\
\text { seed (FPKM) }\end{array}$ & $\begin{array}{l}\text { Expression level } \\
\text { in other tissues } \\
\text { (FPKM) }\end{array}$ \\
\hline tpk2 & LOC_Os01g25440 & 1 & $\begin{array}{l}14398598- \\
14391999\end{array}$ & 268 & $\begin{array}{l}\text { Brachypodium, } \\
\text { Sorghum and } \\
\text { maize }\end{array}$ & Anther/29.5105 & $2.18487 / 3.53966$ & $\begin{array}{l}\text { Embryo at 25DAP } \\
(8.76654)\end{array}$ \\
\hline tpk3 & LOC_Os05g30454 & 5 & $\begin{array}{l}17649664- \\
17644844\end{array}$ & 268 & $\begin{array}{l}\text { Brachypodium, } \\
\text { Sorghum and } \\
\text { maize }\end{array}$ & Shoot/12.8129 & $0 / 0$ & $\begin{array}{l}\text { Pre-emergence } \\
\text { inflorescence } \\
(2.57715)\end{array}$ \\
\hline Putative ncs 1 & LOC_Os02g44680 & 2 & $\begin{array}{l}27077280- \\
27079020\end{array}$ & 539 & $\begin{array}{l}\text { Brachypodium, } \\
\text { Sorghum and } \\
\text { maize }\end{array}$ & $\begin{array}{l}\text { Pre-emergence } \\
\text { inflorescence } \\
\text { /2.86182 }\end{array}$ & 0/0 & Pistil (1.86176) \\
\hline
\end{tabular}


promoter engineering has been suggested for transporters such as Tpk, Put3 or Ncs1. Tissue specific transcriptome information needs to be generated for rice genotypes with contrasting levels of thiamine, to identify novel target genes encoding rate limiting enzymes of thiamine biosynthesis pathway. The CRISPR-Cas9 technology has made gene editing much simpler than ever before, and therefore is highlighted as the method of choice.

\section{AUTHOR CONTRIBUTIONS}

AM initiated the project, collected and analyzed data, wrote the manuscript, RT reshaped the title, designed technical details,

\section{REFERENCES}

Ajjawi, I., Tsegaye, Y., and Shintani, D. (2007). Determination of the genetic, molecular, and biochemical basis of the Arabidopsis thaliana thiamin auxotroph th1. Arch. Biochem. Biophys. 459, 107-114. doi: 10.1016/j.abb.2006.11.011

Andersson, M., Turesson, H., Nicolia, A., Fält, A. S., Samuelsson, M., and Hofvander, P. (2017). Efficient targeted multiallelic mutagenesis in tetraploid potato (Solanum tuberosum) by transient CRISPR-Cas9 expression in protoplasts. Plant Cell Rep. 36:117.

Bae, S., Park, J., and Kim, J. S. (2014). Cas-OFFinder: A fast and versatile algorithm that searches for potential off-target sites of Cas9 RNA-guided endonucleases. Bioinform. 30, 1473-1475. doi: 10.1093/bioinformatics/btu048

Barennes, H., Sengkhamyong, K., and Rene, J. P. (2015). Beriberi (thiamine deficiency) and high infant mortality in northern laos. PLoS Negl. Trop. Dis. 9:e0003581. doi: 10.1371/journal.pntd.0003581

Beatty, P. H., Shrawat, A. K., Carroll, R. T., Zhu, T., and Good, A. G. (2009). Transcriptome analysis of nitrogen-efficient rice overexpressing alanine aminotransferase. Plant Biotech. J. 7, 562-576. doi: $10.1111 / j .1467-7652.2009 .00424 . x$

Belanger, F. C., Leustek, T., and Chu, B. (1995). Evidence for the thiamine biosynthetic pathway in higher-plant plastids and its developmental regulation. Plant Mol. Biol. 29, 809-821. doi: 10.1007/BF00041170

Bettendorff, L., Wirtzfeld, B., and Makarchikov, A. F. (2007). Discovery of a natural thiamine adenine nucleotide. Nat. Chem. Biol. 3, 211-212. doi: $10.1038 /$ nchembio867

Blancquaert, D., Daele, J. V., Strobbe, S., Kiekens, F., Storozhenko, S., De Steur, H., et al. (2015). Improving folate (vitamin $\mathrm{B}_{9}$ ) stability in biofortified rice through metabolic engineering. Nat. Biotech. 33, 1076-1078. doi: 10.1038/ nbt. 3358

Boch, J., Scholze, H., Schornack, S., Landgraf, A., Hahn, S., Kay, S., et al. (2009). Breaking the code of DNA binding specificity of TAL-type III effectors. Science. 326, 1509-1512. doi: 10.1126/science.1178811

Bocobza, S. E., Malitsky, S., and Araujo, W. L. (2013). Orchestration of thiamin biosynthesis and central metabolism by combined action of the thiamin pyrophosphate riboswitch and the circadian clock in Arabidopsis. Plant Cell. 25, 288-307. doi: 10.1105/tpc.112.106385

Bolotin, A., Quinquis, B., Sorokin, A., and Ehrlich, S. D. (2005). Clustered regularly interspaced short palindrome repeats (CRISPRs) have spacers of extrachromosomal origin. Microbiology 151, 2551-2561. doi: 10.1099/mic.0.28048-0

Bonner, J., and Buchman, E. R. (1938). Syntheses carried out in vivo by isolated pea roots. Proc. Nat. Acad. Sci. U.S.A. 24, 431-438. doi: 10.1073/pnas.24.10.431

Carugo, O., Cemazar, M., Zahariev, S., Hudáky, I., Gáspári, Z., Perczel, A., et al. (2003). Vicinal disulfide turns. Prot. Eng. Des. Select. 16, 637-639. doi: 10.1093/protein/gzg088

Chabregas, S. M., Luche, D. D., and Farias, L. P. (2001). Dual targeting properties of the N-terminal signal sequence of Arabidopsis thaliana THI1 protein to mitochondria and chloroplasts. Plant Mol. Biol. 46, 639-650. doi: 10.1023/A:1011628510711 provided expert feedback, reviewed the article critically, SP commented and reviewed the article.

\section{ACKNOWLEDGMENTS}

RT acknowledges DST for JC Bose Fellowship. AM acknowledges Panjab University, TEQIP-III UIET and DST-SERB.

\section{SUPPLEMENTARY MATERIAL}

The Supplementary Material for this article can be found online at: https://www.frontiersin.org/articles/10.3389/fpls.2018. 00975/full\#supplementary-material

Chatterjee, A., Abeydeera, N. D., Bale, S., Pai, P. J., Dorrestein, P. C., and Russell, D. H. (2011). Saccharomyces cerevisiae THI4p is a suicide thiamine thiazole synthase. Nature 478, 542-546. doi: 10.1038/nature10503

Chemnitz, C., and Becheva, S. (2014). Facts and Figures About the Animals We Eat. Meat Atlas 2014. Available online at: https://www.foeeurope.org/sites/default/ files/publications/foee_hbf_meatatlas_jan2014.pdf

Chen, Y., Liu, X., Zhang, Y., Wang, H., Ying, H., Liu, M., et al. (2016). A Self-restricted CRISPR System to Reduce Off-target Effects. Mol. Ther. 24, 1508-1510. doi: 10.1038/mt.2016.172

Colinas, M., and Fitzpatrick, T. B. (2015). Natures balancing act: examining biosynthesis de novo, recycling and processing damaged vitamin B metabolites. Curr. Opin. Plant Biol. 25, 98-106. doi: 10.1016/j.pbi.2015.05.001

Cong, L., Ran, F. A., Cox, D., Lin, S., Barretto, R., Habib, N., et al. (2013). Multiplex genome engineering using CRISPR/Cas systems. Science 339, 819-823. doi: 10.1126/science. 1231143

Croft, M. T., Moulin, M., and Webb, M. E. (2007). Thiamine biosynthesis in algae is regulated by riboswitches. Proc. Natl. Acad. Sci. U.S.A. 104, 20770-20775. doi: 10.1073/pnas.0705786105

Cumming, R. G., Mitchell, P., and Smith, W. (2000). Diet and cataract: the Blue Mountains Eye Study. Ophthalmology 107, 450-456. doi: 10.1016/S0161-6420(99)00024-X

Dash, S., Van Hemert, J., Hong, L., Wise, R. P., and Dickerson, J. A. (2012). PLEXdb: gene expression resources for plants and plant pathogens. Nucl. Aci. Res. 40, D1194-D1201. doi: 10.1093/nar/gkr938.

Dong, W., Stockwell, V. O., and Goyer, A. (2015). Enhancement of thiamin content in Thaliana by Metabolic Engineering. Plant Cell Physiol. 56, 2285-2296. doi: $10.1093 / \mathrm{pcp} / \mathrm{pcv} 148$

Dong, W., Thomas, N., Ronald, P. C., and Goyer, A. (2016). Overexpression of thiamin biosynthesis genes in rice increases leaf and unpolished grain thiamin content but not resistance to Xanthomonas oryzae pv. oryzae. Front. Plant Sci. 7:616. doi: 10.3389/fpls.2016.00616

FAO Statistics Division (2011). Food Balance Sheets: Cambodia 2014. Available online at: http://faostat.fao.org/site/368/DesktopDefault.aspx?PageID=368\# ancor

Galluzzi, L., Vacchelli, E., and Michels, J. (2013). Effects of vitamin B6 metabolism on oncogenesis, tumor progression and therapeutic responses. Oncogene 13, 4995-5004. doi: 10.1038/onc.2012.623

Gangolf, M., Wins, P., and Thiry, M. (2010). Thiamine triphosphate synthesis in rat brain occurs in mitochondria and is coupled to the respiratory chain. J. Biol. Chem. 285, 583-594. doi: 10.1074/jbc.M109.054379

Garneau, J. E., Dupuis, M. Ė., Villion, M., Romero, D. A., Barrangou, R., Boyaval, P., et al. (2010). The CRISPR/Cas bacterial immune system cleaves bacteriophage and plasmid DNA. Nature 468, 67-71. doi: 10.1038/nature09523

Gaj, T., Gersbach, C. A., and Barbas, C. F. (2013). ZFN, TALEN, and CRISPR/Casbased methods for genome engineering. Trends Biotechnol. 31, 397-405. doi: 10.1016/j.tibtech.2013.04.004

Gehrmann, J., Alewood, P. F., and Craik, D. J. (1998). Structure determination of the three disulfide bond isomers of $\alpha$-conotoxin GI: a model for the role of disulfide bonds in structural stability. J. Mol. Biol. 278, 401-405. 
Ghosh, M., Anthony, C., Harlos, K., Goodwin, M. G., and Blake, C. (1995). The refined structure of the quinoprotein methanol dehydrogenase from Methylobacterium extorquens at $1.94 \mathrm{~A}^{\circ}$. Structure 3, 177-187.

Gołda, A., Szyniarowski, P., and Ostrowska, K. (2004). Thiamine binding and metabolism in germinating seeds of selected cereals and legumes. Plant Physiol. Biochem. 42, 187-195. doi: 10.1016/j.plaphy.2004.01.002

Global Nutrition Report (2016). From Promise to Impact: Ending Malnutrition by 2030. Washington, DC: International Food Policy Research Institute (IFPRI).

Goyer, A., and Sweek, K. (2011). Genetic diversity of thiamin and folate in primitive cultivated and wild potato (Solanum) species. Agric. Food Chem. 59, 13072-13080. doi: 10.1021/jf203736e

Hamada, K., Hongo, K., Suwabe, K., Shimizu, A., Nagayama, T., Abe, R., et al. (2011). OryzaExpress: An Integrated Database of Gene Expression Networks and Omics Annotations in Rice. Plant Cell Physiol. 52, 220-229. doi: $10.1093 / \mathrm{pcp} / \mathrm{pcq} 195$

Heigwer, F., Kerr, G., and Boutros, M. (2014). E-CRISP: fast CRISPR target site identification. Nature Meth. 11, 122-123. doi: 10.1038/nmeth.2812

Hellmann, H., and Mooney, S. (2010). Vitamin B6: a molecule for human health? Molecules 15, 442-459. doi: 10.3390/molecules 15010442

Higo, K., Ugawa, Y., Iwamoto, M., and Korenaga, T. (1999). Plant cis-acting regulatory DNA elements (PLACE) database. Nucl. Acids Res. 27, 297-300. doi: $10.1093 /$ nar/27.1.297

Hsu, P. D., Lander, E. S., and Zhang, F. (2014). Development and applications of CRISPR-Cas9 for genome engineering. Cell 157, 1262-1278. doi: 10.1016/j.cell.2014.05.010

Jacques, P. F., Taylor, A., Moeller, S., Hankinson, S. E., Rogers, G., and Tung, W. (2005). Long-term nutrient intake and 5-year change in nuclear lens opacities. Arch. Ophth. 123, 517-526. doi: 10.1001/archopht.123.4.517

Ji, X., Zhang, H., Zhang, Y., Wang, Y., and Gao, C. (2015). Establishing a CRISPRCas-like immune system conferring DNA virus resistance in plants. Nat. Plants 1:15144. doi: $10.1038 /$ nplants.2015.144

Joint FAO/WHO Expert Consultation (2004). Vitamin and Mineral Requirements in Human Nutrition, 2nd Edn. Geneva: World Health Organization.

Jones, H. D. (2015). Regulatory uncertainty over genome editing. Nat. Plants 1:14011. doi: 10.1038/nplants.2014.11

Jiang, W. Z., Henry, I. M., Lynagh, P. G., Comai, L., Cahoon, E. B., and Weeks, D. P. (2016). Significant enhancement of fatty acid composition in seeds of the allohexaploid, Camelina sativa, using CRISPR/ Cas9 gene editing. Plant Biotech. J. 15, 648-657. doi: 10.1111/pbi.12663

Kawahara, Y., Oono, Y., Wakimoto, H., Ogata, J., Kanamori, H., Sasaki, H., et al. (2016). TENOR: Database for Comprehensive mRNA-Seq Experiments in Rice. Plant Cell Physiol. 57:e7. doi: 10.1093/pcp/pcv179

Kawakatsu, T., Masayuki, P., Yamamoto, S. H., Hirose, S., Yano, M., Takaiwa, F.,(2008). Characterization of a new rice glutelin gene GluD-1 expressed in the starchy endosperm. J. Exp. Bot. 59, 4233-4245. doi: 10.1093/jxb/ern265.

Keating, E. M., Nget, P., and Kea, S. (2014). Thiamine deficiency in tachypnoeic Cambodian infants. Paediatr. Int. Child Health 35, 312-318. doi: 10.1179/2046905514Y.0000000162

Kong, D., Zhu, Y., Wu, H., Cheng, X., Liang, H., and Ling, H. Q. (2008). AtTHIC, a gene involved in thiamine biosynthesis in Arabidopsis thaliana. Cell Res. 18, 566-576. doi: 10.1038/cr.2008.35

Le, Q. Q., Yan, P. X., Wen, X. L., Xiu, P. X., and Yan, R. S. (2008). Expression pattern and activity of six glutelin gene promoters in transgenic rice. J. Exp. Bot. 59, 2417-2424. doi: 10.1093/jxb/ern110

Li, M., Li, X., Zhou, Z., Wu, P., Fang, M., Pan, X., et al. (2016a). Reassessment of the four yield related genes Gn1a, DEP1, GS3, and IPA1 in rice using a CRISPR/Cas9 system. Front. Plant Sci. 7:377. doi: 10.3389/fpls.2016. 00377

Li, Q., Zhang, D., Chen, M., Liang, W., Wei, J., Qi, Y., et al. (2016b). Development of japonica photo-sensitive genic male sterile rice lines by editing Carbon Starved Anther using CRISPR/Cas9. J. Gene. Geno. 43, 415-419. doi: 10.1016/j.jgg.2016.04.011

Li, Z., Liu, Z. B., Xing, A., Moon, B. P., Koellhoffer, J. P., and Huang, L. (2015). Cas9-guide RNA directed genome editing in Soybean. Plant Physiol. 169, 960-970. doi: 10.1104/pp.15.00783

Machado, C. R., de Oliveira, R. L., and Boiteux, S. (1996). Thil, a thiamine biosynthetic gene in Arabidopsis thaliana, complements bacterial defects in DNA repair. Plant Mol. Biol. 31, 585-593. doi: 10.1007/BF00042231
Marraffini, L. A., and Sontheimer, E. J. (2008). CRISPR interference limits horizontal gene transfer in Staphylococci by targeting DNA. Science 322, 1843-1845. doi: 10.1126/science.1165771

Martinis, J., Gas-Pascual, E., Szydlowski, N., Crevecoeur, M., Gisler, A., Burkle, L., et al. (2016). Long-distance transport of thiamine (vitamin $\mathrm{B}_{1}$ ) is concomitant with that of polyamines. Plant Physio. 171, 542-553. doi: 10.1104/pp.16.00009

Mayer, J. E., Pfeiffer, W. H., and Beyer, P. (2008). Biofortified crops to alleviate micronutrient malnutrition. Curr. Opin. Plant Biol. 11, 166-170. doi: 10.1016/j.pbi.2008.01.007

Mitsuda, H., Takii, Y., and Iwami, K. (1979). Enzymatic formation of thiamine pyrophosphate in plants. Meth. Enzymol. 62, 107-111. doi: 10.1016/0076-6879(79)62202-4

Mohd Fairulnizal, M. N., Norhayati, M. K., Zaiton, A., Norliza, A. H., Rusidah, S., Aswir, A. R., et al. (2015). Nutrient content in selected commercial rice in Malaysia: an update of Malaysian food composition database. Inter. Food Res. J. 22, 768-776.

Mojica, F. J., Diez-Villasenor, C., Garcia-Martinez, J., and Soria, E. (2005). Intervening sequences of regularly spaced prokaryotic repeats derive from foreign genetic elements. J. Mol. Evol. 60, 174-182. doi: 10.1007/s00239-004-0046-3

Molin, W. T., and Fites, R. C. (1980). Isolation and characterization of thiamine pyrophosphotransferase from Glycine max Seedlings. Plant Physiol. 66, 308-312. doi: 10.1104/pp.66.2.308

Moscou, M. J., and Bogdanove, A. J. (2009). A simple cipher governs DNA recognition by TAL effectors. Science 326, 1501. doi: 10.1126/science.11 78817

Moulin, P., Cinq-Frais, C., and Gangloff, C. (2014). Thiamine deficiency in infants: a case report. Arch. Pediatr. 21, 392-395. doi: 10.1016/j.arcped.2014.01.009

Murugan, K., Babu, K., Sundaresan, R., Rajan, R., and Sashital, D. G. (2017). The Revolution Continues: Newly Discovered Systems Expand the CRISPR-Cas Toolkit. Mol. Cell. 68, 15-25. doi: 10.1016/j.molcel.2017.09.007

Nie, D. M., Ouyang, Y. D., Wang, X., Zhou, W., Hu, C. G., and Yao, J. (2013). Genome-wide analysis of endosperm-specific genes in rice. Gene 10, 236-247. doi: 10.1016/j.gene.2013.07.088

Pabo, C. O., Peisach, E., and Grant, R. A. (2001). Design and selection of novel Cys2His2 zinc finger proteins. Annu. Rev. Biochem. 70, 313-340. doi: 10.1146/annurev.biochem.70.1.313

Pan, C. T., Ye, L., Qin, L., Liu, X., He, Y. J., Wang, J., et al. (2016). CRISPR/Cas9mediated efficient and heritable targeted mutagenesis in tomato plants in the first and later generations. Sci. Rep. 6:24765. doi: 10.1038/srep24765

Park, C., and Raines, R. T. (2001). Adjacent cysteine residues as a redox switch. Protein Eng. 14, 939-942. doi: 10.1093/protein/14. 11.939

Porter, S. G., Coats, D., and Fischer, P. R. (2014). Thiamine deficiency and cardiac dysfunction in Cambodian infants. J. Pediatr. 164, 1456-1461. doi: 10.1016/j.jpeds.2014.01.049

Pourcel, L., Moulin, M., and Fitzpatrick, T. B. (2013). Examining strategies to facilitate vitamin B1 biofortification of plants by genetic engineering. Front. Plant Sci. 4:160. doi: 10.3389/fpls.2013.00160

Rabbani, N., Alam, S. S., Riaz, S., Larkin, J. R., Akhtar, M. W., and Shafi, T. (2009). High-dose thiamine therapy for patients with type 2 diabetes and microalbuminuria: a randomised, double-blind placebo-controlled pilot study. Diabetologia 52, 208-212. doi: 10.1007/s00125-008-1224-4

Rapala-Kozik, M., Gołda, A., and Kujda, M. (2009). Enzymes that control the thiamine diphosphate pool in plant tissues. Properties of thiamine pyrophosphokinase and thiamine-(di) phosphate phosphatase purified from Zea mays seedlings. Plant Physiol. Biochem. 47, 237-242. doi: 10.1016/j.plaphy.2008.12.015

Raschke, M., Burkle, L., Muller, N., Nunes-Nesi, A., Fernie, A. R., Arigoni, D., et al (2007). Vitamin B1 biosynthesis in plants requires the essential ironsulfur cluster protein, THIC. Proc. Natl. Acad. Sci. U.S.A. 104, 19637-19642. doi: 10.1073/pnas.0709597104

Ribeiro, D. T., Farias, L. P., de Almeida, J. D., Kashiwabara, P. M., Ribeiro, A. F., and Silva-Filho, M. C. (2005). Functional characterization of the thil promoter region from Arabidopsis thaliana. J. Exp. Bot. 56, 1797-1804. doi: $10.1093 /$ jxb/eri168

Robbins, W. J., and Bartley, M. A. (1937). Vitamin B1 and the growth of excised tomato roots. Science 85, 246-247. doi: 10.1126/science.85.2201.246 
Rodionov, D. A., Vitreschak, A. G., Mironov, A. A., and Gelfand, M. S. (2002). Comparative genomics of thiamin biosynthesis in procaryotes. New genes and regulatory mechanisms. J. Biol. Chem. 277, 48949-48959. doi: 10.1074/jbc.M208965200

Sato, Y., Antonio, B., Namiki, N., Takehisa, H., Minami, H., Kamatsuki, K., et al. (2011a). RiceXPro: a platform for monitoring gene expression in japonica rice grown under natural field conditions. Nucl. Acid. Res. 39, D1141-D1148. doi: 10.1093/nar/gkq1085

Sato, Y., Antonio, B. A., Namiki, N., Motoyama, R., Sugimoto, K., Takehisa, H., et al. (2011b). Field transcriptome revealed critical developmental and physiological transitions involved in the expression of growth potential in japonica rice. BMC Plant Biol. 11:10. doi: 10.1186/1471-2229-11-10

Sato, Y., Takehisa, H., Kamatsuki, K., Minami, H., Namiki, N., Ikawa, H., et al. (2013). RiceXPro Version 3.0: expanding the informatics resource for rice transcriptome. Nucl. Acid. Res. 41, D1206-D1213. doi: 10.1093/nar/gks1125

Sautter, C., Poletti, S., and Zhang, P. (2006). Biofortification of essential nutritional compounds and trace elements in rice and cassava. Proc. Nutr. Soc. 65, 153-159. doi: 10.1079/PNS2006488

Steiger, G., Muller-Fischer, N., Cori, H., and Conde-Petit, B. (2014). Fortification of rice: technologies and nutrients. Ann. N.Y. Acad. Sci. 1-11. doi: 10.1111/nyas. 12418

Takehisa, H., Sato, Y., Igarashi, M., Abiko, T., Antonio, B. A., Kamatsuki, K., et al. (2012). Genome-wide transcriptome dissection of the rice root system: implications for developmental and physiological functions. Plant J. 69, 126-140. doi: 10.1111/j.1365-313X.2011.04777.x

Thompson, J. D., Gibson, T. J., Plewniak, F., Jeanmougin, F., and Higgins, D. G. (1997). The ClustalX windows interface: flexible strategies for multiple sequence alignment aided by quality analysis tools. Nucl. Acid. Res. 25, 4876-4882. doi: 10.1093/nar/25.24.4876

USDA (2013). United States Department of Agriculture Foreign Agricultural Service Approved by the World Agricultural Outlook. Washington, DC: Board/USDA.

Waltz, E. (2016). Gene-edited CRISPR mushroom escapes US regulation. Nature 21, 532. doi: 10.1038/nature.2016.19754

Waltz, E. (2018). With a free pass, CRISPR-edited plants reach market in record time. Nat. Biotech. 36, 6-7. doi: 10.1038/nbt0118-6b

Wang, G., Ding, X., Yuan, M., Qiu, D., Li, X., and Xu, C. (2006). Dual function of rice OsDR8 gene in disease resistance and thiamine accumulation. Plant Mol. Biol. 60, 437-449. doi: 10.1007/s11103-005-4770-x
Wang, S., Zhang, S., Wang, W., Xiong, X., Meng, F., and Cui, X. (2015). Efficient targeted mutagenesis in potato by the CRISPR/Cas9 system. Plant Cell Rep. 34, 1473-1476. doi: 10.1007/s.00299-015-1816-7

Wang, X. H., Connor, M., Smith, R., Maciejewski, M. W., Howden, M. E. H., Nicholson, G. M., et al. (2000). Discovery and characterization of a family of insecticidal neurotoxins with a rare vicinal disulfide bridge. Nat. Struct. Biol. 7 , 505-513. doi: 10.1038/75921

Wang, Y., Cheng, X., Shan, Q., Zhang, Y., Liu, J., and Gao, C. (2014). Simultaneous editing of three homoeoalleles in hexaploid bread wheat confers heritable resistance to powdery mildew. Nat. Biotechnol. 32, 947-951. doi: 10.1038/nbt.2969

Whitfield, K. C., Smith, G., Chamnan, C., Karakochuk, C. D., Sophonneary, P., Kuong, K., et al. (2017). High prevalence of thiamine (vitamin B1) deficiency in early childhood among a nationally representative sample of Cambodian women of childbearing age and their children. PLoS Negl. Trop. Dis. 11:e0005814. doi: 10.1371/journal.pntd.0005814

WHO/NHD (1999). Thiamine Deficiency and Its Prevention and Control in Major Emergencies. WHO/NHD/99.13.

Wooley, J. A. (2008). Characteristics of thiamin and its relevance to the management of heart failure. Nutr. Clin. Pract. 23:487-493. doi: $10.1177 / 0884533608323430$

Wu, C. Y., Suzuki, A., Washida, H., and Takaiwa, F. (1998). The GCN4 motif in a rice glutelin gene is essential for endosperm-specific gene expression and is activated by Opaque-2 in transgenic rice plants. Plant J. 14, 673-683.

Zhu, C., Naqvi, S., and Gomez-Galera, S. (2007). Transgenic strategies for the nutritional enhancement of plants. Trends Plant Sci. 12, 548-555. doi: $10.1016 /$ j.tplants.2007.09.007

Conflict of Interest Statement: The authors declare that the research was conducted in the absence of any commercial or financial relationships that could be construed as a potential conflict of interest.

Copyright (C) 2018 Minhas, Tuli and Puri. This is an open-access article distributed under the terms of the Creative Commons Attribution License (CC BY). The use, distribution or reproduction in other forums is permitted, provided the original author(s) and the copyright owner(s) are credited and that the original publication in this journal is cited, in accordance with accepted academic practice. No use, distribution or reproduction is permitted which does not comply with these terms. 